\title{
Toxicity Assessment of Heavy Metals in Soils around Transformers in University of Port Harcourt, Choba, Nigeria
}

\author{
Ayomide Adetutu Idowu, *Godson Ndubuisi Iwuoha \\ Department of Pure and Industrial Chemistry, Faculty of Science, University of Port Harcourt, Choba, Nigeria
}

*Corresponding Author: Godson Ndubuisi Iwuoha, Department of Pure and Industrial Chemistry, Faculty of Science, University of Port Harcourt, Choba, Nigeria

\begin{abstract}
The presence of Heavy metals in soil both in high and low concentrations can exhibit toxic effects towards the biota present in the soil, and its uptake can present risks to humans, animals, plants and the entire ecosystems in various ways. This research was conducted to measure the loading of some heavy metals and assess its toxicity potentials in soils around transformer sites in the University of Port Harcourt. This was done in order to ascertain if the transformers possess toxicity threat with respect to Nickel, Iron Chromium Lead and Copper and in need of replacement. In order to conduct the studies, samples of soils were collected from four transformer sites of University of Port Harcourt. Samples were analyzed using Atomic Absorption Spectroscopy (BUCK SCIENTIFIC, MODEL 210VGP), to estimate the total concentration of the selected heavy metals. The designated sites were four in number $A, B, C$, and $D$ with geography co-ordinates. For site A-Donald Ekong Library, site B-Senate building site C-Transformer at music department and site D-GanaMa Lecturers residential quarters. All sites showed no toxicity due to due to Nickel, Chromium Lead and Copper and are in no need for clean up or remediation for the above heavy metals but the soils' Iron concentrations in the four sites exceeded average concentration of 2.94 ppm of iron required in the earth's top soil.
\end{abstract}

Keywords: Trace Metals, Toxicological Effect, Toxicity, Transformers

\section{INTRODUCTION}

Transformers has inbuilt dielectric substances and various forms of oils that serve various functions. In addition to transformer metal wares, these oils contain trace amount of various heavy metals which could leak and constitute environmental problems by adding up to the soil's concentration. Soils have been found to be the major sink for heavy metals when released into the environment. It has been noted that most heavy metals do not undergo microbial or chemical degradation because they are nondegradable and as a result, there is bioaccumulation of their total concentrations after being released to the environment and it affects the food chain [1],[2],[3].

Heavy metal refers to any metallic chemical element that has a relatively high density of more than $5.0 \mathrm{~g} / \mathrm{cm}^{3}$ atomic weights or atomic numbers and is toxic or poisonous at low concentrations. Heavy metals are natural components of the earth's crust and cannot be destroyed nor be degraded [4]. Some heavy metals are either essential nutrients (typically iron, cobalt, and zinc), or relatively harmless (such as ruthenium, silver, and indium), but in larger amounts or certain forms heavy metals can be toxic and could potentially trigger toxicological effect on exposure of the site soil on human contact. Heavy metals tend to bioaccumulate hence they are dangerous to living organism. In living organisms, accumulation is said to occur when compounds are taken up and stored faster than they are being catabolized. Bioaccumulation can be referred to as increase in the amount of a chemical in an organism, in comparison with the concentration of the chemical in the environment over time [5].

The pollution of the environment by heavy metals which could result in food contamination caused the awareness cadmium toxicity which led to a disease called itai itai, and also, the consumption of shell fish contaminated by heavy metals in Japan resulted in the minimata disease. Grasses and edible plants contaminated by heavy metals eventually endanger the food chain due to potential heavy metal toxicity [6], [7]. 
Toxicity Assessment of Heavy Metals in Soils around Transformers in University of Port Harcourt, Choba, Nigeria

In this study, toxicity of heavy metals such as Nickel $(\mathrm{Ni})$, Chromium $(\mathrm{Cr})$, Lead $(\mathrm{Pb})$, Copper $(\mathrm{Cu})$ and Iron $(\mathrm{Fe})$, which are present in the transformer metal wares and at trace levels in the various oils used in the transformer could to released to the soil and serve as possible sites of contaminations to man and environment, would be investigated.

\section{Material AND MethodS}

\subsection{Sample Collection and Sampling Sites}

The top soil samples were collected randomly around the transformer vicinity within the University of Port Harcourt by scooping the depths of about $2 \mathrm{~cm}$ each. Ample amount of the top soil was collected in amber glass bottles and designated sample A, B, C, and D for sites A, B, C and D with geographical coordinates of site A-Donald Ekong Library to be latitude $4^{\circ} 54,32$ '' $\mathrm{N}$ and longitude $6^{\circ} 55: 05^{\prime}$ 'E, site B- Senate building with latitude $4^{\circ} 54^{\prime} 14 \mathrm{~N}$ and longitude $6{ }^{\circ} 55 ; 23^{\prime}$ 'N, site Ctransformer close to music department with latitude $4^{\circ} 54 ; 01^{\prime}$ ' $\mathrm{N}$ and longitude $6^{\circ} 55 ; 56^{\prime \prime} \mathrm{E}$ and site D- GanaMa Lecturers residential quarters with latitude $4{ }^{\circ} 54 ; 23^{\prime \prime} \mathrm{N}$ and longitude $6{ }^{\circ} 55 ; 74^{\prime \prime} \mathrm{E}$. the samples were kept in a refrigerator until they were analyzed. Reagents and apparatus used include: Stock standard solution, Hydrochloric acid, Nitric acid, weighing balance (OHAUS MODEL PA2146), laboratory heating mantle (SUNBIM, MODEL 62PA), Atomic Absorption Spectrometer (BUCK SCIENTIFIC, MODEL 210VGP), electric oven, heating mantle, $2 \mathrm{ml}$ amber screw cap vials and glass wares (Beakers, conical flasks)

\subsection{Analytical Procedure}

The samples were first air-dried and placed in an electric oven at a temperature of $40^{\circ} \mathrm{C}$ approximately for 30 minutes. They were then homogenized having been ground and sieved through sieves of stainless steel of $2 \mathrm{~mm}$ mesh. $1 \mathrm{~g}$ of the samples was collected in the conical flasks, followed by $10 \mathrm{ml}$ aqua-regia (i.e. mixture of $\mathrm{HCl}$ and $\mathrm{HNO}_{3}$ in ratio 3:1), the samples were then placed on a heating mantle and allowed to digest. After digestion, followed by cooling, $20 \mathrm{ml}$ of deionized water was added to the digest. The content of the conical flask was then stirred thoroughly and filtered. The filtrates were collected in a clean and well labeled sample container for AAS analysis.

\section{RESULTS AND DISCUSSION}

The toxicity evaluation of the soils around selected transformers areas included heavy metal toxicity assessment of the soil. The heavy metals in view are Nickel, Iron, Chromium, Lead and copper. Their various concentrations are shown in the table below.

Table1. The Concentration of Heavy Metals (ppm) in Soils around Transformer Installations in University Of Port Harcourt.

\begin{tabular}{|l|l|l|l|l|l|}
\hline SAMPLE & Ni & Fe & Cr & Pb & Cu \\
\hline A & 1.72 & 15.00 & $<0.01$ & $<0.01$ & 0.62 \\
\hline B & $<0.01$ & 5.00 & $<0.01$ & $<0.01$ & $<0.01$ \\
\hline C & 3.45 & 10.00 & 0.56 & $<0.01$ & 1.03 \\
\hline D & 1.72 & 5.00 & $<0.01$ & $<0.01$ & 0.41 \\
\hline
\end{tabular}

The table generally indicates no toxicity threat of the heavy metals especially when these are correlated with the respective Average heavy metal composition in the earth soil [8].

\subsection{Nickel (Ni)}

Nickel was not detected in the soil around the transformer at the Senate building and has the highest value of $3.45 \mathrm{ppm}$ in Site D (Soil around transformer at Music Department). It recorded same value of $1.72 \mathrm{ppm}$ at site B and site C (i.e. Donald Ekong library transformer soil area and Ganama transformer soil area). The high value at site D could be attributed to the surface topography of the site area. The transformer in this site is located in a relatively lower plane (small valley), hence runoff water or flood can easily transport available and soluble Nickel to this spot which adds to the Nickel associated with the fuel and oil used in the maintenance of the transformer. The minimum safe level of Nickel in average earth soil is $27 \mathrm{ppm}$ (Table 2.0), hence all the soil sites are relatively free from Nickel toxicity of the soil. Toxicological symptoms in humans associated with Nickel toxicity includes: Reduced sperm count, Eczema, Acute lung injury and Dermatitis are not expected for the inhabitants or people exposed to the soils around these transformer sites [8], [9],[10]. 
Toxicity Assessment of Heavy Metals in Soils around Transformers in University of Port Harcourt, Choba, Nigeria

\subsection{Iron (Fe)}

The concentration of Iron across the four sites is worrisome in view of the average minimum value of the Iron required for earth top soil i.e. $2.94 \mathrm{ppm}$. Site A and C has $15 \mathrm{ppm}$ and $10 \mathrm{ppm}$ which exceeded the baseline requirement for iron in the earth top soil. Although there have been vast report of elevated concentration of iron in the surface water and rock formations in the Niger-Delta area. One can also reason that the rusting of iron frame work of the transformer parts in this two sites are additives to the already high iron contents in the soil formation. The transformers in this two sites is open to rain, moisture and harsh weather unlike those situated at site B and D (i.e. Senate and Ganama). With the above trend of results, humans are exposed potentially to iron toxicity of which symptoms includes vomiting, hemorrhage, metabolic acidosis and cardiac depression [8].

\subsection{Chromium $(\mathrm{Cr})$}

Chromium was not detected in any of the soil sites around the transformers except for site $\mathrm{C}(0.56$ ppm) as values were below the detection limit of the machine used (i.e. $0.01 \mathrm{ppm}$ ). The minimum average required for chromium on the top soil is $61 \mathrm{ppm}$ [8]; hence no toxicology symptoms of Chromium are expected on any human directly in contact with the soils around any of these sites. Chromium toxicity includes acute renal failure, pulmonary and lung cancer.

\subsection{Lead $(\mathrm{Pb})$}

Lead followed a similar trend with chromium but it was not detected at all in sites A to D. Toxicological symptoms due to lead are not expected for humans and animals directly exposed to any of the sites around these transformers. Lead toxicological symptoms include; high blood pressure, reduced intelligent quotient, anemia, kidney damage and behavioral problems. The minimum average lead requirement in earth's top soil is 26 ppm [8], [11], [12], [13], [14].

\subsection{Copper (Cu)}

Copper was detected at sites A, C and D with concentration of $0.62 \mathrm{ppm}, 1.03 \mathrm{ppm}$ and $0.41 \mathrm{ppm}$ respectively. Toxicity due to direct human contact with these soils are not expected because the concentrations are by far below average minimum copper levels of $23 \mathrm{ppm}$ required for earth's top soil. Copper was not detected in soil at site B. the toxicological symptoms associate with copper includes; shortage of blood, irritation and blue vomits [8], [11], [15].

\section{CONCLUSION}

Most of the selected heavy metals (i.e. Nickel, Chromium Lead and Copper) concentrations in the soil around transformers will be safe for direct exposure to human contact as they did not exceed their respective average minimum required level in earth's top soil. Iron in all the four sites exceeded average minimum required concentration of $2.94 \mathrm{ppm}$ on earth's top soil and could potentially trigger toxicological effect on exposure of the site soil to human contact. This may not be due to the transformers entirely as it also could be heavily attributed to the mineral and geological composition of iron in the soil of Niger-Delta region. Location of transformers at lower plain (Valleys) should be avoided and efforts should be made to reduce rusting of the metal wares of the transformers and also to reduce transport of iron to the soil which could lead to iron toxicity. The results generally indicates that the soils around transformer sites are not associated with heavy metal toxicity.

Table2. The composition of average soil and its related material in ppm. [8]

\begin{tabular}{|l|l|l|l|l|l|}
\hline & Ni & Fe & Cr & Pb & Cu \\
\hline $\begin{array}{l}\text { The composition } \\
\text { of average soil } \\
\text { and its related } \\
\text { material in ppm. }\end{array}$ & & 2.94 & 61 & 26 & 23 \\
\hline
\end{tabular}


Toxicity Assessment of Heavy Metals in Soils around Transformers in University of Port Harcourt, Choba, Nigeria

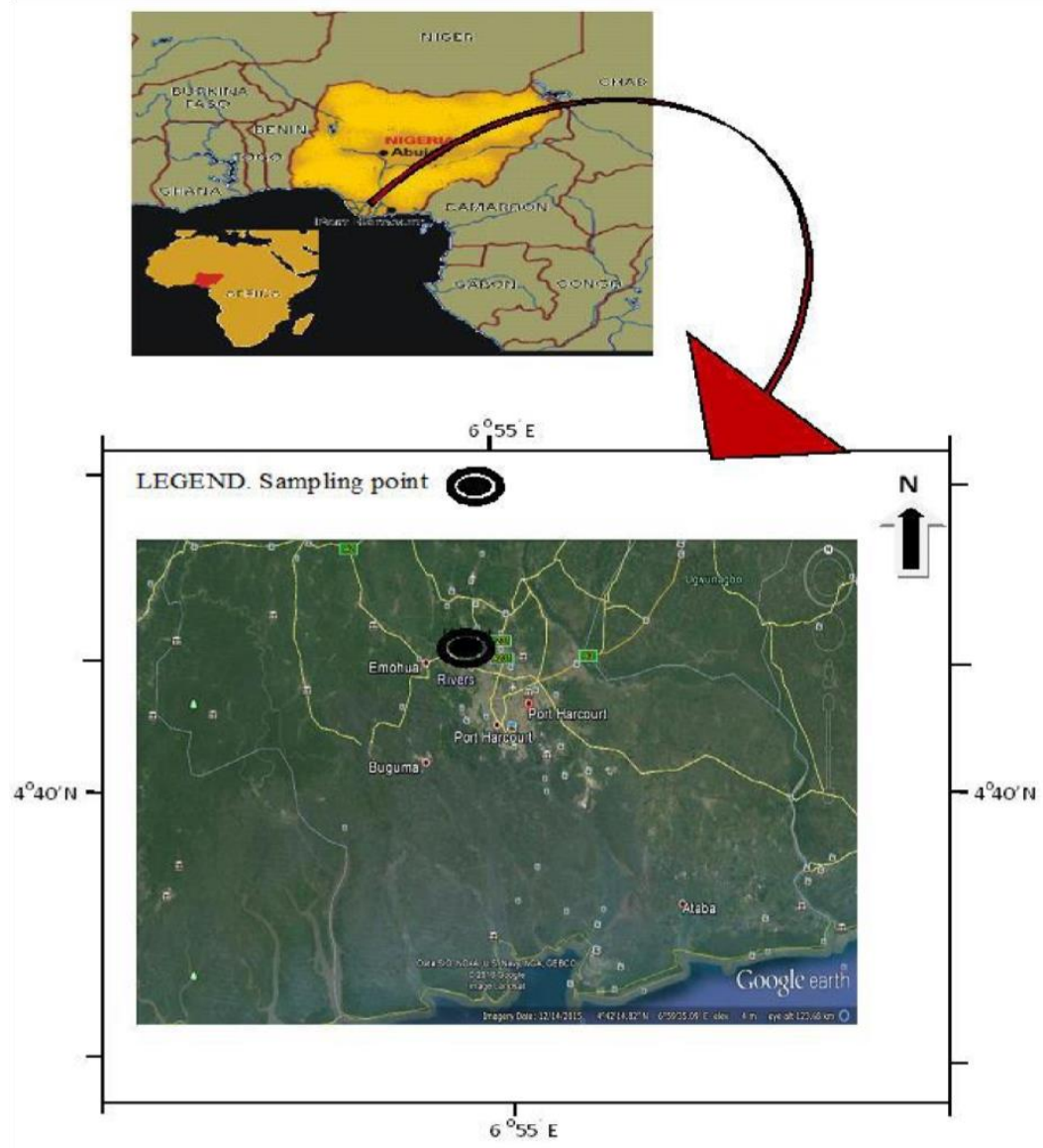

Figure1. Map showing sampling location (University of Port Harcourt, Rivers State)

\section{REFERENCES}

[1] Lepp N.W. (2012) Effect of heavy metal pollution on plants. Metals in the Environment, Pollution Monitoring Series,(2) Department of Biology. Liverpool, United Kingdom: Liverpool Polytechnic; Applied Science Publishers.

[2] Ahmad, A.G., Abdul-Wahab, O.E., and Mohammed, K. H. (2008). Determination of selected heavy metals in air samples from the northern part of Jordan. Environmental Monitoring and Assessment.160(14), 425-429

[3] Anyinam, C.A. (1991). Transboundary movement of Hazardous waste: the case of toxic waste dumping in Africa. International journal of Health Service, 21 (4),759-777.

[4] Koller, M., and Saleh, H.M. (2018).Introducing Heavy metals. Heavy Metals. Retrieved from http://www.interchopen.com.

[5] Horsfall, M., and Spiff, A.I. (2013). Principles of Environmental Pollution, Toxicology and waste Management:Environmental Chemistry ( $1^{\text {st }}$ d) Port Harcourt, Rivers: Onyoma Research.

[6] Adetutu, I.A. Iwuoha, G.N., and Horsfall, M. (2020).Carcinogenicity of dioxin-like polychlorinated biphenyls in transformer soil in vicinity of University of PortHarcourt, Choba, Nigeria.Chemistry International Bosal Journals6(3), 144-150

[7] Musilova, J., Arvay, J., Vollmannova, A., Toth, T., and Tomas, J. (2016) Environmental contamination by heavy metals in region with previous mining activity. Bulletin of Environmental Contamination and Toxicology 97, 569-575

[8] Turekain, K.K. Wedepohl, K.H (1961). Distribution of elements in some units of the earth's crust. Geol. Soc of Am. Bull., 72, 175-192

[9] Raskin, I., Kuma, P. B., Dushenkov, R. S., and Salt, D.E. (1994) "Bioconcentration of heavy metals by plants," Current Opinion in Biotechnology, 5(3). 285-290.

[10] Haber L.T., Erdreicht L., Diamond G.L., Maier A.M., Ratney R., Zhao Q., and Dourson M.L.

(2000).Hazard identification and dose response of inhaled nickel-soluble salts. Regulatory. Toxicology and .Pharmacology,31(2), 210-230. DOI:10.1006/rtph.2000.1377 
Toxicity Assessment of Heavy Metals in Soils around Transformers in University of Port Harcourt, Choba, Nigeria

[11] Herawati N., Suzuki S., Hayashi K., Rivai I.F., and Koyoma H. (2000).Cadmium, copper and zinc levels in rice and soil of Japan, Indonesia and China by soil type.Bulletin of Environmental Contamination and Toxicology. 64, 33-39.

[12] Saeed, S., Marzieh, V.D., Akbar, H., and Toba K. (2014). Heavy Metals in Water and Sediment: A Case Study of Tembi River. Journal of Environmental and Public Health 14, 1-5.Article ID 858720, .doi:10.1155/2014/8587202992927

[13] Stojic, N., Pucarevic, M.M., Mrkajic, D.,Kecojevic, I. (2014).Transformers as a potential for soil contamination. Researchgate. Retrieved from https://www.researchgate.net/publication/263673715 Transformes_as_a_potential_for_soil_contamination

[14] Tiwari, S., and Tripathi, I.P. (2012). Lead Pollution -An Overview, Int. Res. J. Environment Sci., 1(5), 84- 86.

[15] Wallace, W. G. (1996). Acclimation and adaptation to pollutants: effects on metal trophic transfer. Ph.D. dissertation. State University of New York at Stony Brook

Citation: Ayomide Adetutu Idowu \& Godson Ndubuisi Iwuoha ."Toxicity Assessment of Heavy Metals in Soils around Transformers in University of Port Harcourt, Choba, Nigeria", International Journal of Advanced Research in Chemical Science (IJARCS), vol. 8, no.1, pp. 30-34, 2021. http://dx.doi.org/ 10.20431/2455-7153.0801004

Copyright: (C) 2021 Authors. This is an open-access article distributed under the terms of the Creative Commons Attribution License, which permits unrestricted use, distribution, and reproduction in any medium, provided the original author and source are credited. 